\title{
Isothiourea-Catalyzed Regioselective Acylative Kinetic Resolution of Axially Chiral Biaryl Diols
}

\author{
Shen Qu, Mark. D. Greenhalgh and Andrew. D. Smith*[a]
}

\begin{abstract}
An operationally-simple isothiourea-catalyzed acylative kinetic resolution of unprotected 1,1'-biaryl-2,2'-diol derivatives has been developed to allow access to axially chiral compounds in highly enantioenriched form ( $s$ values up to 190). Investigation of the reaction scope and limitations provided three key observations: i) the diol motif of the substrate was essential for good conversion and high $s$ values; ii) the use of an $\alpha, \alpha$-disubstituted mixed anhydride (2,2-diphenylacetic pivalic anhydride) was critical to minimize diacylation and give high selectivity; iii) the presence of substituents in the 3,3'-positions of the diol hindered effective acylation. This final observation was exploited for the highly regioselective acylative kinetic resolution of unsymmetrical biaryl diol substrates bearing a single 3-substituent. Based on the key observations identified, acylation transition state models have been proposed to explain the atropselectivity of this kinetic resolution.
\end{abstract}

\section{Introduction}

Axially chiral biaryl structures are present in many natural products and pharmaceuticals, ${ }^{[1]}$ and have been used as chiral ligands and auxiliaries in a range of applications. ${ }^{[2]}$ Axially chiral biaryl compounds derived from 1,1'-bi-2-naphthol (BINOL), including 2-amino-2'-hydroxy-1,1'-binaphthyl (NOBIN) and 2,2'bis(diphenylphosphino)-1,1'-binaphtyl (BINAP), have found particularly widespread use in asymmetric catalysis. ${ }^{[3]}$ Enantiopure samples of these axially chiral biaryl compounds are typically prepared through classical stoichiometric resolution methods, and as such there is current interest in the development of alternative routes to these important compounds. ${ }^{[4]}$ The catalytic enantioselective synthesis of BINOL derivatives can be achieved through the oxidative homocoupling of naphthols, ${ }^{[5]}$ however some limitations in substrate scope and enantioselectivity makes the development of alternative methods attractive. Recently a number of catalytic methods have been reported for the kinetic resolution $(\mathrm{KR})^{[6]}$ of $\mathrm{O}$ - and/or $\mathrm{N}$ protected BINOL and NOBIN derivatives ${ }^{[7]}$ using enzymes, ${ }^{\left[{ }^{[3]}\right.}$ transition metals, ${ }^{[9]}$ and organocatalysts. ${ }^{[10]}$ Despite this interest, small molecule Lewis base catalyzed acylative KRs of these substrates has not been widely explored. ${ }^{[11]}$ Sibi has reported the acylative KR of mono-protected biaryl diols using a fluxionally chiral DMAP catalyst with moderate to good selectivity factors ${ }^{[12]}$ (Scheme 1a, $\left.s=10-50\right),{ }^{[13]}$ however the KR of unprotected chiral biaryl diols remains surprisingly underdeveloped. To the best of our knowledge, only one such method has been reported by Zhao by utilizing NHC redox catalysis (Scheme 1b). ${ }^{[14]}$ Although proceeding with excellent selectivity in many examples, this method provided a mixture of

[a] S. Qu, Dr M. D. Greenhalgh, Prof. Dr A. D. Smith EaStCHEM, School of Chemistry, University of St Andrews North Haugh, St Andrews, Fife, KY16 9ST (UK)

E-mail: ads10@st-andrews.ac.uk

Supporting information for this article is given via a link at the end of the document. regioisomeric ester products when using unsymmetricallysubstituted diol substrates.

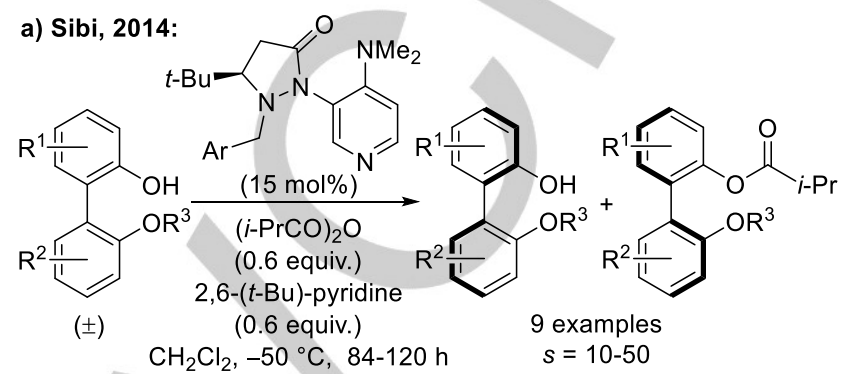

b) Zhao, 2014:

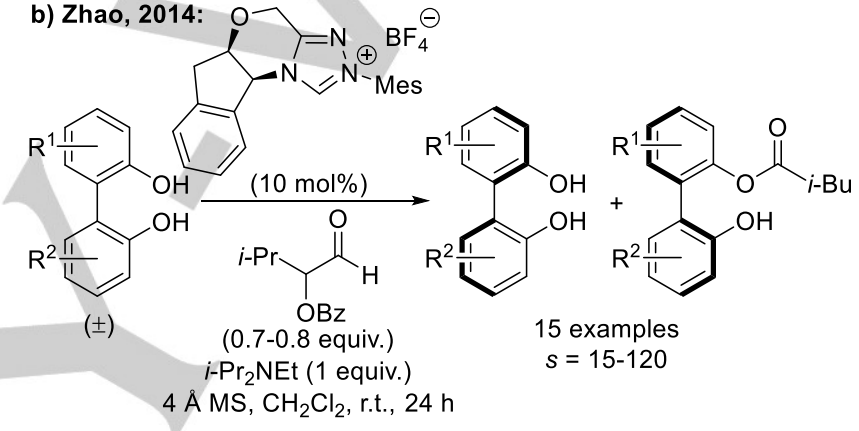

Scheme 1. Lewis based-catalyzed acylative KRs of biaryl diol derivatives.

Lewis basic isothioureas catalysts, ${ }^{[15]}$ first reported for acyl transfer reactions by Birman and Okamoto, ${ }^{[16]}$ have been applied for the acylative KR of primary, ${ }^{[17]}$ secondary ${ }^{[18]}$ and tertiary ${ }^{[19]}$ alcohols bearing point chirality. The KR of secondary alcohols has been most widely explored, with exceptional selectivities obtained in many cases. Computational studies have been used to probe the origin of enantiodiscrimination in these KRs, with acylation transition state structure (TS) models proposed for the fast- and slow-reacting enantiomers (Scheme 2a). ${ }^{[18 \mathrm{~h}-\mathrm{j}, \mathrm{m}, \mathrm{n}, \mathrm{p}, \mathrm{q}, \mathrm{19}, 1 \mathrm{a}, 20]}$ Three key features are generally highlighted: i) a 1,5-S $\cdots O$ interaction, which locks the acyl group syn-coplanar with the isothiouronium core; ${ }^{[21]}$ ii) chelation of the carboxylate counterion, which engages in a non-classical $\mathrm{C}-\mathrm{H} \cdots \mathrm{O}$ hydrogen bond with the acidic $\mathrm{C}(2)-\mathrm{H}$ of the acylated catalyst and simultaneously deprotonates the alcohol; ${ }^{[20,22]}$ and iii) electrostatic stabilization of the isothiouronium ion by an electron-rich substituent on the alcohol (commonly a $\pi$-system or a substituent bearing a lone pair of electrons). The preferential acylation of the fast-reacting enantiomer of the alcohol is then generally rationalized based on reduced steric hindrance in the acylation transition state.

Based on this mechanistic model, we hypothesized that isothiourea catalysis may be applicable for the atropselective acylative KR of axially chiral biaryl diols (Scheme 2b). Considering possible TSs for the acylation of each enantiomer of BINOL, it was expected that the extended $\pi$-system of BINOL, in addition to the potential for the formation of additional hydrogen bonding interactions (present in TS-I), may provide an opportunity for enantiodiscrimination. Herein we report the development of this method for the highly regio- and 
atropselective KR of unprotected 1,1'-biaryl-2,2'-diol derivatives to provide access to biaryl diols in highly enantioenriched form.

a) Established KR of point chiral secondary alcohols

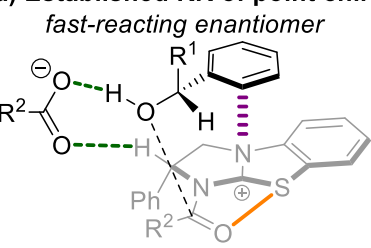

slow-reacting enantiomer

Common features:

S.• O interaction

ii) Hydrogen bonding by carboxylat

iii) $\pi \bullet \bullet$ isothiouronium interaction

b) This work: Atropselective KR of axially chiral biaryl diols
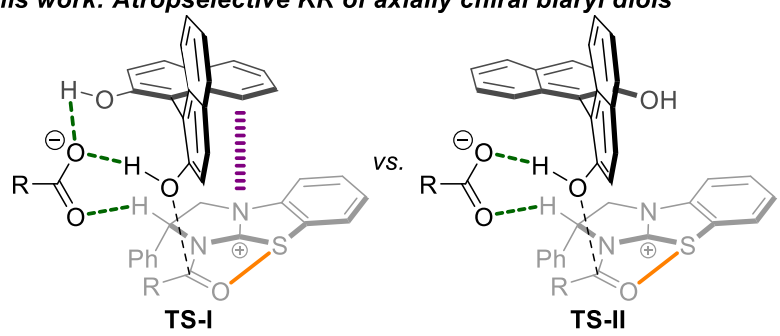

Enhanced $\pi \bullet \bullet$ isothiouronium interaction

Additional hydrogen bond

$\rightarrow$ fast-reacting enantiomer?

Scheme 2. Proposed transition state structures (TSs) for the acylation of point chiral secondary alcohols (a) and axially chiral biaryl diols (b).

\section{Results and Discussion}

\subsection{Reaction optimization}

Method development began with the KR of commerciallyavailable ( \pm )-BINOL 1 using three isothiourea catalysts: HyperBTM 4, ${ }^{[23]}$ tetramisole $(\mathrm{TM} \cdot \mathrm{HCl}) \mathbf{5}$ and BTM $\mathbf{6},{ }^{[16 a]}$ all at 1 mol\% catalyst loading (Table 1 ). Initial investigations used isobutyric anhydride $7 \mathbf{a}$ as the acyl donor, $i-\mathrm{Pr}_{2} \mathrm{NEt}$ as auxiliary base and chloroform as solvent, as this combination is commonly optimal for the KR of point chiral alcohols. ${ }^{[16-19]}$ All three catalysts provided good conversion (c $=54-58 \%$, entries $1-3$ ), however only BTM 6 provided good selectivity ( $s=26$, entry 3$)$. When using (R)-BTM 6 as catalyst, the recovered BINOL was enriched in the $(R)$-enantiomer $(R)-1$, consistent with the proposed acylation TS models (Scheme $2 b$ ). In addition to BINOL 1 and the expected monoester product $\mathbf{2 a}$, small amounts $(\sim 1 \%)$ of diester $\mathbf{3} \mathbf{a}$, enriched in the $(S)$-enantiomer, were also obtained. Control reactions found that acylation of monoester $\mathbf{2} \mathbf{a}$ to give diester $\mathbf{3} \mathbf{a}$ takes place via a second $\mathrm{KR}$, albeit with low selectivity $(s<2) .{ }^{[24]}$ Due to the operation of this second $K R$, all subsequent $s$ values were calculated using the er of recovered BINOL 1 and the reaction conversion, which was determined by ${ }^{1} \mathrm{H}$ NMR spectroscopic analysis of the crude reaction product mixture.

The use of alternative reaction solvents was examined next (entries 4-11). In contrast to chloroform, the use of dichloromethane provided only low selectivity ( $s=5$, entry 4$)$. The use of ethereal solvents provided mixed results: THF gave low selectivity ( $s=9$, entry 5 ), however diethyl ether and diisopropyl ether provided good levels of selectivity ( $s=20-22$, entries 6-7), albeit still slightly lower than that obtained using chloroform. The use of industrially-preferable solvents was investigated next. ${ }^{[25]}$ Whilst ethyl acetate and acetone provided relatively low selectivities $(s=11-12$, entries $8-9)$, toluene $(s=$
18, entry 10), and in particular tert-amyl alcohol $(s=34$, entry 11) provided good to high levels of selectivity. Notably, the choice of solvent not only affected the selectivity of the KR, but also had a significant effect on the amount of diester 3a produced. Very little diester (1-2\%) was obtained when using halogenated or hydrocarbon solvents, however the use of ethers, esters, alcohols and ketones provided significantly higher quantities of diester (up to 10\%), suggesting that diester formation may be promoted by the hydrogen bond acceptor ability of the solvent. ${ }^{[26]}$

Further control studies found that high conversions were still obtained in the absence of catalyst, indicating the possibility of a competitive racemic base-mediated acylation pathway. ${ }^{[24]}$ The $\mathrm{KR}$ of $\mathrm{BINOL}$ in the absence of $i-\mathrm{Pr}_{2} \mathrm{NEt}$ was therefore investigated in both tert-amyl alcohol and $\mathrm{CHCl}_{3}$. The $\mathrm{KR}$ in tertamyl alcohol provided very similar conversion and selectivity in comparison to the reaction in the presence of base (c $=50, s=$ 37 , entry 12). In contrast, the KR in chloroform was significantly improved in the absence of base, with good conversion (c = $49 \%)$ and high selectivity $(s=40)$ obtained. Notably, the formation of diester $3 a$ was also inhibited under these conditions.

Table 1: Reaction optimization I: Variation of catalyst and solvent.

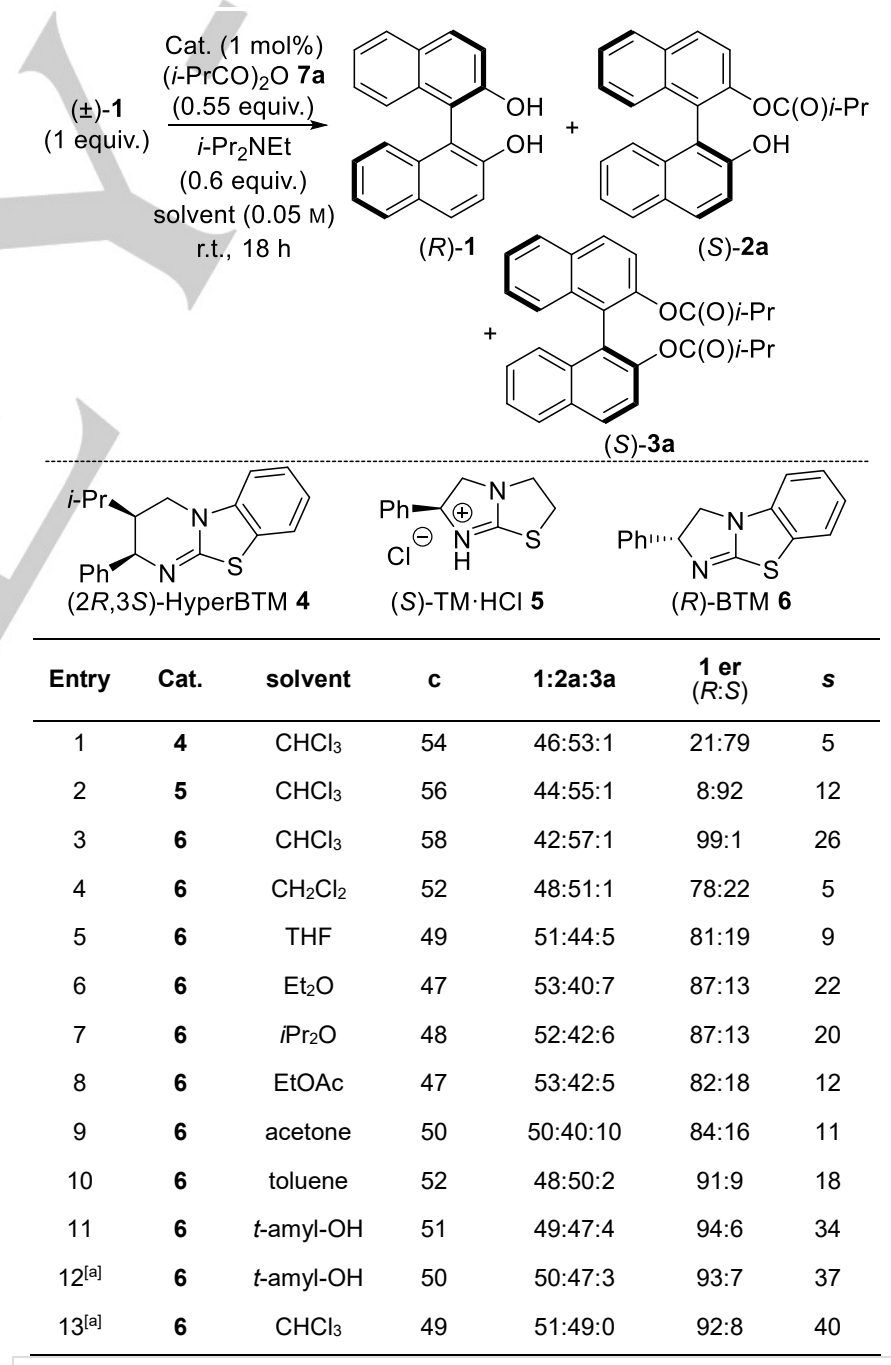

Conversion (c) and product ratio determined by ${ }^{1} \mathrm{H}$ NMR spectroscopic analysis of the crude reaction product mixture. er determined by chiral HPLC analysis. $s$ calculated using equations given in ref. 6 . [a] no $i-\mathrm{Pr}_{2} \mathrm{NEt}$ used. 
The choice of anhydride is known to have a significant effect on enantiodiscrimination in the KR of point chiral alcohols. This effect is most commonly rationalized by a change in the steric nature of the acyl group undergoing transfer; however the role of the carboxylate counterion in aiding preorganization of the acylation TS and promoting deprotonation of the alcohol should not be overlooked (highlighted in Scheme 2). ${ }^{[20,22]}$ Due to the lack of fundamental studies on the acylative KR of axially chiral alcohols, a broad investigation of anhydride structure for the KR of BINOL 1 was conducted. These studies were performed using both chloroform and tert-amyl alcohol as solvent, with similar selectivities obtained in both solvent systems. As such, only the results obtained using chloroform are discussed in the following section, with the results obtained using tert-amyl alcohol available in the Supporting Information. ${ }^{[24]}$

The effect of anhydride choice was investigated under the conditions previously optimized for isobutyric anhydride $\mathbf{7 a}$, which had provided good conversion and high selectivity (c $=49$, $s=40$ ) (Table 1, entry 13). Decreasing the steric bulk of the anhydride to propionic anhydride $\mathbf{7 b}$ led to reduced selectivity ( $s$ $=14$, table 2 , entry 1 ); whilst increasing the steric bulk to pivalic anhydride $7 \mathrm{c}$ resulted in a loss in activity, with only $2 \%$ conversion obtained (entry 2). As the branched nature of isobutyric anhydride appeared advantageous, the use of homoanhydrides with alkyl substituents at the $\beta$ - or $\gamma$-carbon was investigated (entries 3-4). In each case, selectivities similar to that observed when using propionic anhydride were obtained ( $s$ $=8-11$ ), consistent with branching at the $\alpha$-carbon being most influential for inducing high selectivity. The introduction of an aromatic substituent at the $\alpha$ - or $\beta$-carbon was also investigated. The use of dihydrocinnamic anhydride $\mathbf{7 g}$ provided similar results to propionic anhydride ( $s=11$, entry 6$)$, however improved selectivity was obtained using phenylacetic anhydride 7f $(s=21$, entry 5$)$, again consistent with increased steric hindrance at the $\alpha$-carbon leading to improved selectivity. Homoanhydrides bearing an $\mathrm{sp}^{2}$-hybridized carbon at the $\alpha$ position were next tested. Cinnamic anhydride $7 \mathrm{~h}$ provided very poor selectivity ( $s=3$, entry 7 ), however improved selectivities were obtained using benzoic anhydride derivatives $\mathbf{7 i}-\mathbf{7} \mathbf{k}$ and nicotinic anhydride $7 \mathrm{I}(s=15-21$, entries $8-11)$.

As isobutyric anhydride $7 \mathrm{a}$ had provided the highest selectivity and the lowest amount of diester $3 \mathbf{a}$, the use of alternative $\alpha, \alpha-$ disubstituted homoanhydrides was investigated. While both diethyl acetic anhydride $7 \mathrm{~m}$ and dipropyl acetic anhydride $\mathbf{7 n}$ provided relatively low conversions $(c=12-15 \%$, entries $12-13$ ), similar selectivities to that obtained when using isobutyric anhydride were achieved ( $s=34-37$ ). Diphenyl acetic anhydride 7o provided an improvement in selectivity $(s=43)$, and crucially also provided excellent conversion $(c=52 \%)$. Cyclic anhydrides were also tested, however neither cyclopentane carboxylic anhydride $\mathbf{7 p}$ nor cyclohexane carboxylic anhydride $\mathbf{7 q}$ provided any further improvement ( $s=23-34$, entries 15-16).

The optimal conversion and high selectivity obtained using diphenylacetic anhydride 7o, and the lack of reactivity using pivalic anhydride $7 c$, presented the possibility of using the mixed anhydride 2,2-diphenylacetic pivalic anhydride 7r. Mixed anhydrides have been reported to be advantageous in some cases for the $K R$ of point chiral secondary alcohols. ${ }^{[18 b, d, h, j, m, n, p, q, 20 b, 27]}$ Generating the mixed anhydride in situ from diphenylacetic acid and pivalic anhydride provided a
KR protocol that gave excellent selectivity $(s=50-60)$ but inconsistent reaction conversion in our hands $(c=8-42 \%){ }^{[24]}$ This irreproducibility was circumvented by using the isolated mixed anhydride, 2,2-diphenylacetic pivalic anhydride 7r, which can be readily prepared and stored as a bench-stable solid. Good conversion and excellent selectivity were reproducibly obtained for the KR of BINOL (c $=50 \%, s=50$ ) (Table 2, entry 17). ${ }^{[28]}$ Further investigation of reaction temperatures in the range of -40 to $45{ }^{\circ} \mathrm{C}$ confirmed the highest selectivity was obtained at room temperature. ${ }^{[24]}$

Table 2: Reaction optimization II: Variation of anhydride.

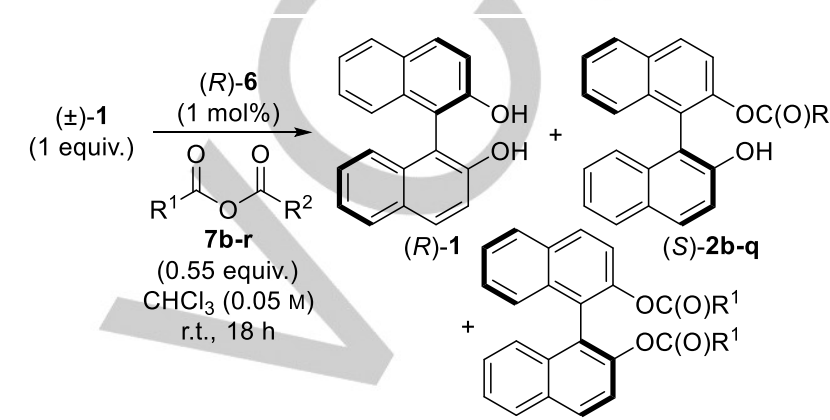

(S)-3b-q

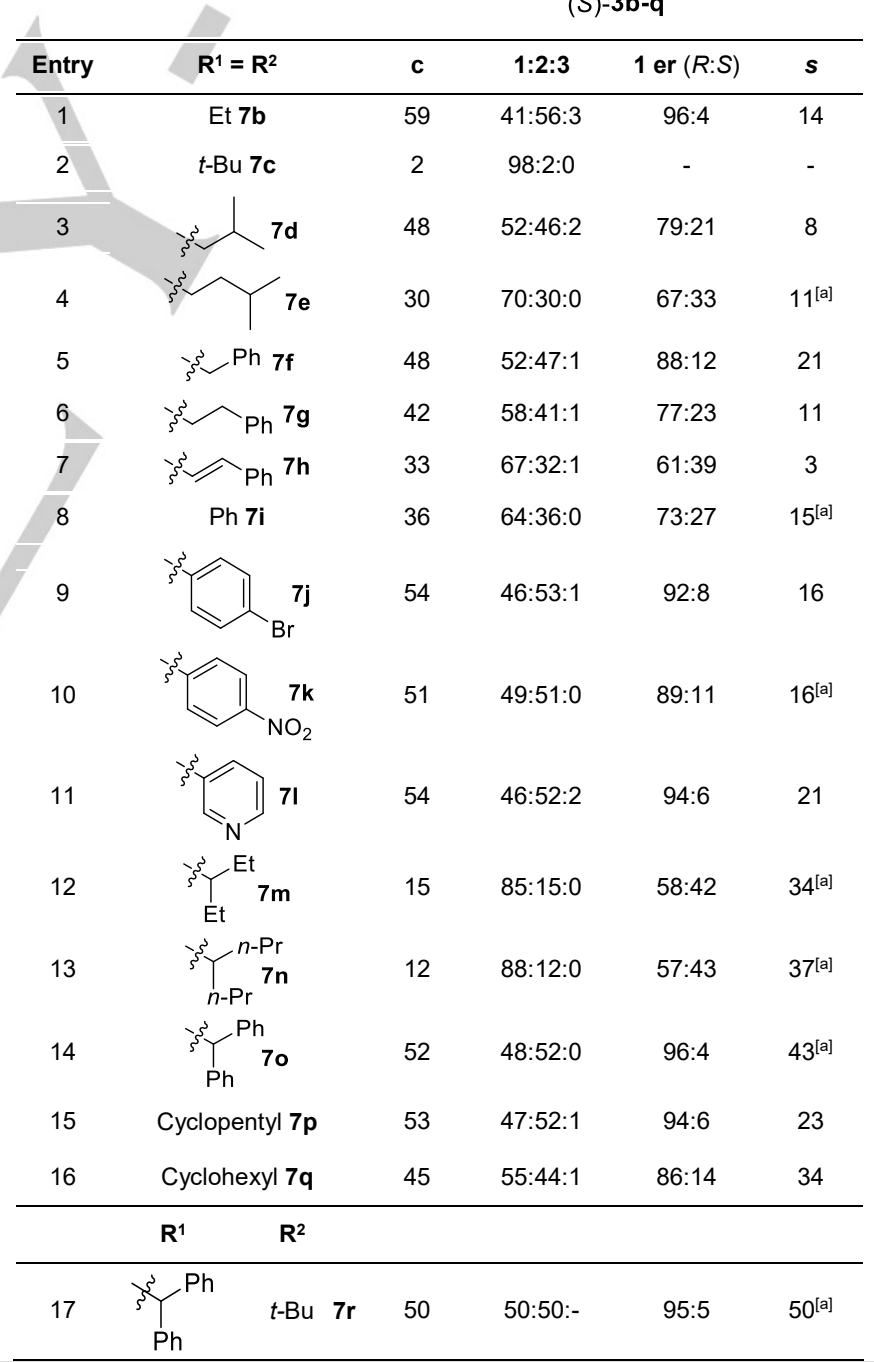

Conversion (c) and product ratio determined by ${ }^{1} \mathrm{H}$ NMR spectroscopic analysis of the crude reaction product mixture. er determined by chiral HPLC analysis. $s$ calculated using equations given in ref. 6. [a] As no diester formation observed, $s$ was calculated using the ers of recovered $\mathbf{1}$ and $\mathbf{2}$. 
To showcase the applicability of the optimized KR procedure, the resolution of $( \pm)$-BINOL was conducted on a preparative scale (Scheme 3). The KR of $1.43 \mathrm{~g}$ of BINOL 1 was achieved with comparable conversion and selectivity as that obtained on an analytical scale $(\mathrm{c}=50 \%, s=50)$, allowing enantioenriched $(R)$-BINOL $(R)-1$ to be recovered in $46 \%$ yield $(0.66 \mathrm{~g}, 95: 5 \mathrm{er}$ ).

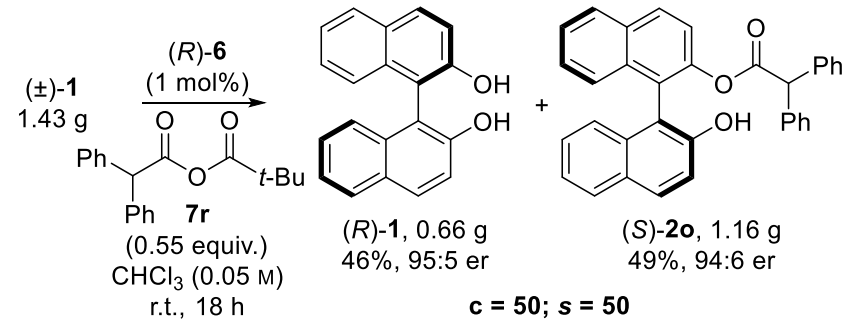

Scheme 3. Gram-scale KR of $( \pm)$-BINOL 1

\subsection{Reaction scope and limitations}

The generality of the KR procedure was explored using a collection of biaryl diols (Tables 3 and 4). In each case no formation of any diester products was observed and therefore $s$ values were calculated using the er of the recovered diol and monoester products. 7,7'-Dimethoxy-substituted BINOL derivative 8 underwent KR with ideal conversion and excellent selectivity (Table $3, s=60$ ). Whilst 7,7'-dibromo-substituted derivative 9 underwent resolution with good conversion ( $\mathrm{c}=$ $54 \%$ ), significantly lower selectivity was observed ( $s=10$ ), indicating the selectivity of this KR procedure is sensitive to the electronic effects of the substituents. Introduction of the bromo substituents at the 6,6'-positions however led to much improved selectivity $(10, s=25)$, whilst maintaining good conversion. The $\mathrm{KR}$ of BINOL derivatives with $3 / 3^{\prime}$-substitution proved more challenging. [9,9'-Biphenanthrene]-10,10'-diol 11 was significantly more difficult to acylate, with only $23 \%$ conversion obtained when using $10 \mathrm{~mol} \%$ catalyst loading, albeit with an acceptable $s$ value of 11 . The attempted KR of $3,3^{\prime}$-dimethyl ester-substituted BINOL derivative 12 proved unsuccessful, with no conversion observed using either HyperBTM 4 or BTM 6 at up to $10 \mathrm{~mol} \%$ catalyst loading. The use of higher reaction temperatures and less sterically-hindered anhydrides also failed to promote the acylation of diol $\mathbf{1 2}$. This difficultly in acylating 3,3'-disubstituted BINOL derivatives is consistent with the proposed acylation TS models, where a $3 / 3$ '-substituent would be expected to introduce an unfavourable steric contact with the acyl group of the acylated catalyst (Scheme 2b).

Next, the KR of biphenyl diol derivatives was investigated (Table 4). The KR of $\mathrm{H}_{8}$-BINOL 13 using (R)-BTM 6 provided only low selectivity $(s=3)$, and required a $10 \mathrm{~mol} \%$ catalyst loading to achieve good conversion (see Supporting Information). ${ }^{[24]}$ This can be rationalized considering the proposed transition state models (Scheme 2b), with the semi-hydrogenation of BINOL leading to increased steric hindrance and a loss of the stabilising $\pi$-isothiouronium interactions present in proposed TS-I. Significantly improved results were obtained when using the alternative isothiourea catalyst (2R,3S)-HyperBTM 4 (1 mol\%, c $=38, s=10)$, Interestingly, the pseudo-enantiomeric isothiourea catalysts $(R)$-BTM 6 and $(2 R, 3 S)$-HyperBTM 4 both preferentially acylated $(S)-\mathrm{H}_{8}-\mathrm{BINOL} 13$. This indicates the $\mathrm{KR}$ of $\mathrm{H}_{8}$-BINOL 13 using $(2 R, 3 S)$-HyperBTM 4 proceeds via a different favoured acylation transition state, which may resemble TS-II (Scheme $2 b)$. It is worth noting that the pseudo-enantiomeric forms of the
Table 3. Scope: Symmetrically-substituted binaphthyl diol derivatives.

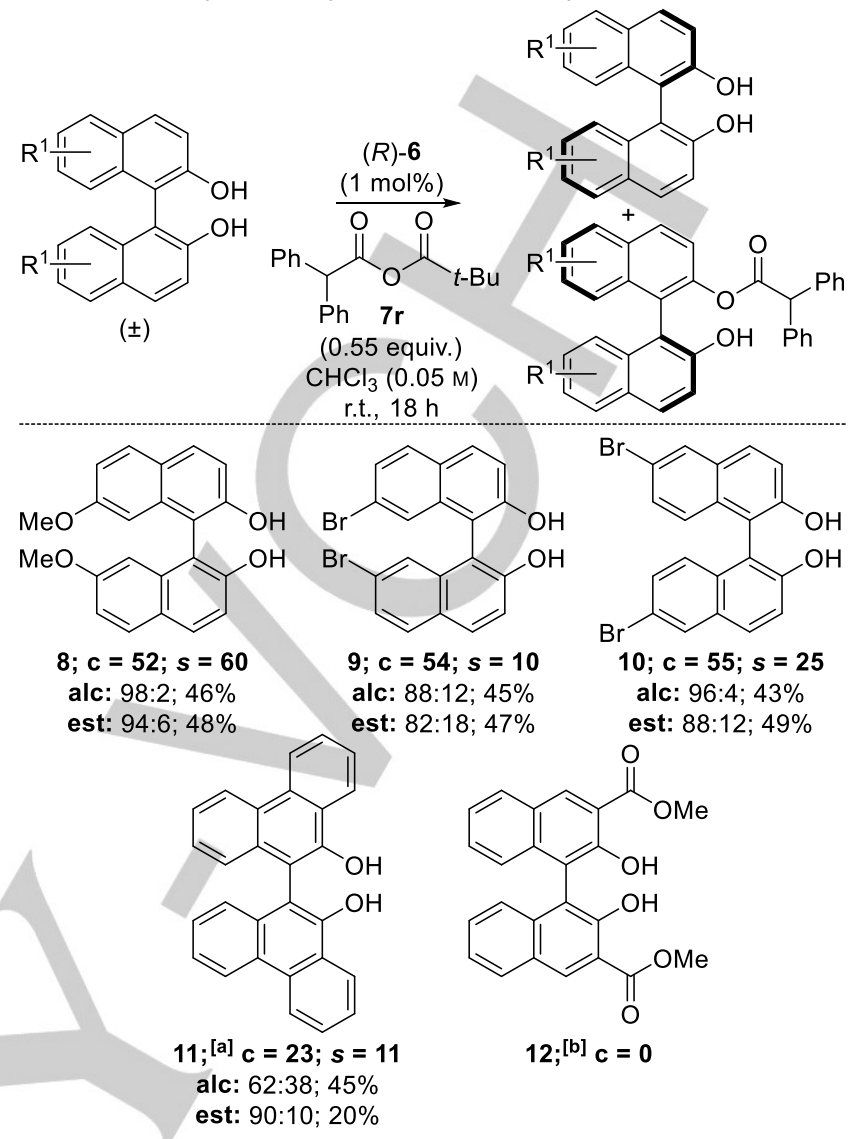

Conversion (c) and er determined by chiral HPLC analysis. $s$ calculated using equations given in ref. 6 . [a] $10 \mathrm{~mol} \%(R)$-BTM 6 used. [b] Using either 10 mol\% $(R)$-BTM 6 or $(2 R, 3 S)$-HyperBTM 4 with 2,2-diphenylacetic pivalic anhydride $7 \mathrm{r}$ or $(\mathrm{MeCO})_{2} \mathrm{O}$ at up to $65^{\circ} \mathrm{C}$.

Table 4. Scope: Symmetrically-substituted biphenyl diol derivatives<smiles>[R][R4]c1cccc(OC(=O)C(c2ccccc2)c2ccccc2-c2ccccc2O)c1-c1ccccc1O</smiles>
$\mathrm{CHCl}_{3}(0.05 \mathrm{M})$, r.t., $18 \mathrm{~h}$<smiles>Oc1ccc2c(c1-c1c(O)ccc3c1CCCC3)CCCC2</smiles>

$13 ;{ }^{[\mathrm{a}]} \mathrm{c}=\mathbf{3 8} ; s=10$
alc: $73: 27 ; 46 \%$ alc: $73: 27 ; 46 \%$
est: $87: 13 ; 36 \%$<smiles>Cc1ccc(O)c(-c2c(O)ccc(C)c2C)c1C</smiles>

14; $c=48 ; s=37$ alc: $91: 9 ; 44 \%$ est: $94: 6 ; 40 \%$<smiles>Cc1cc(O)c(-c2c(O)cc(C)c(Cl)c2C)c(C)c1Cl</smiles>

$15 ; c=48 ; s=13$

alc: $85: 15 ; 48 \%$ est: $87: 13 ; 40 \%$
Conversion (c) and er determined by chiral HPLC analysis. $s$ calculated using equations given in ref. 6 . [a] $1 \mathrm{~mol} \%(2 R, 3 S)$-HyperBTM 4 used. [b] Using either $10 \mathrm{~mol} \%(R)$-BTM 6 or $(2 R, 3 S)$-HyperBTM 4 with 2,2-diphenylacetic pivalic anhydride $7 \mathrm{r}$ or $(\mathrm{MeCO})_{2} \mathrm{O}$ at up to $65^{\circ} \mathrm{C}$

catalysts gave the 'expected' opposite enantiodiscrimination for the acylative $\mathrm{KR}$ of $\mathrm{BINOL} 1$, indicating that comparable transition state models may be proposed in this case (see Table 
1 , entries 1 and 3 ). The scope was explored further through the $\mathrm{KR}$ of biphenyl diol derivatives 14 and 15, which were resolved with good conversion and selectivity $(c=48 \%, s=13-37)$. For the KR of these substrates, BTM 6 proved the optimal choice of catalyst, with (R)-BTM 6 displaying enantiodiscrimination for acylation of the $(S)$-enantiomer of the substrate in each case. ${ }^{[29]}$ To better understand the origin of selectivity in this KR process, the $\mathrm{KR}$ of a selection of mono-protected BINOL derivatives was investigated (Table 5). The KR of racemic monoester $\mathbf{2 0}$ was inefficient, with only $11 \%$ conversion and an $s$ value of 1.1 obtained under the standard reaction conditions. This low conversion is consistent with the observation that diester 3o was not obtained under standard conditions for the KR of BINOL (Table 2, entry 17). Next, the KR of O-methyl-BINOL derivative 16 was investigated. Under standard conditions only $20 \%$ conversion was obtained, with up to $39 \%$ conversion achievable when using a $5 \mathrm{~mol} \%$ catalyst loading. Once again the selectivity of this KR was very low $(s=3)$. These results suggest that the presence of two hydroxyl groups in the substrate may be required to facilitate both good reactivity and selectivity. It was hypothesized that these hydroxyl groups may operate as hydrogen bond donors, and therefore the KR of $N$-Boc protected NOBIN derivative 17, which contains a free $\mathrm{N}-\mathrm{H}$ bond, was investigated. Under the standard KR conditions excellent conversion $(c=49 \%)$ and reasonable selectivity $(s=17)$ were obtained, consistent with the requirement for two hydrogen bond donors in the substrate. These results indicate that this additional hydrogen bond donor may be essential for stabilization of the acylation TS-I to promote effective acylation and enantiodiscrimination (Scheme $2 b$ ).

Table 5. Scope: Mono-protected BINOL derivatives.<smiles>[R]c1ccc2ccccc2c1-c1c(O)ccc2ccccc12</smiles>

$( \pm)$

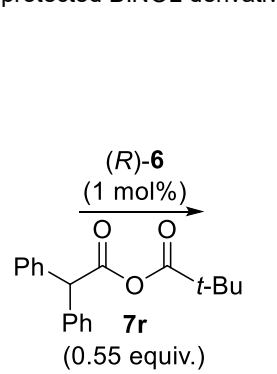

(0.55 equiv. $\mathrm{CHCl}_{3}(0.05 \mathrm{M})$ r.t., $18 \mathrm{~h}$<smiles>C1CC2CCCC2C1</smiles>
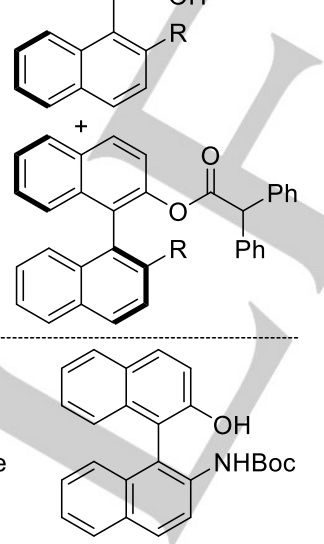

$17 ; \mathrm{c}=49 ; \mathrm{s}=17$ alc: $86: 14 ; 48 \%$ alc: $50: 50 ; 84 \%$ est: $52: 48 ; 5 \%$
$16 ;{ }^{[a]} \mathrm{c}=39 ; s=3$ alc: $64: 36 ; 60 \%$ est: $72: 28 ; 35 \%$ est: $89: 11 ; 31 \%$
Conversion (c) and er determined by chiral HPLC analysis. $s$ calculated using equations given in ref. 6 . [a] $5 \mathrm{~mol} \%$ (R)-BTM 6 used.

Based on the significantly lower conversions obtained when using BINOL derivatives bearing 3,3'-substituents, it was hypothesized that regioselective acylation may be possible for the KR of asymmetrically-substituted biaryl diols bearing just a single 3-substituent. 3-Bromo-substituted BINOL 18 underwent efficient $\mathrm{KR}$ with good conversion $(\mathrm{c}=52 \%$ ) and excellent selectivity $(s=49)$. Only a single ester product was obtained, with regioselective acylation taking place at the less stericallyhindered alcohol. Notably, the acylation of BINOL derivative 18 using 4-dimethylaminopyridine (DMAP) in our hands, or according to Zhao's previous KR methodology, ${ }^{[14]}$ provides a mixture of both monoester constitutional isomers. The scope of the current method was therefore further probed. 3-Phenylsubstituted BINOL derivative 19 also underwent regioselective acylation, with the KR achieved with good conversion (c = 51\%) and exceptional selectivity $(s=190)$, allowing $(R)-19$ to be recovered in essentially enantiopure form (> 99:1 er). Finally, the $\mathrm{KR}$ of 3-methyl ester-substituted BINOL derivative 20 was investigated. Although highly regioselective acylation was observed, a significantly lower $s$ value of 4 was obtained. ${ }^{1} \mathrm{H}$ NMR spectroscopic analysis of diol 20 reveals a significant downfield signal for the hydroxyl group ortho to the ester substituent $\left(\delta_{\mathrm{H}}=10.9 \mathrm{ppm}\right)$, indicative of an intramolecular hydrogen bond. We hypothesize that the low $s$ value obtained for this substrate is therefore consistent with the proposal that this hydroxyl group is required to operate as a hydrogen bond donor in acylation TS-I to promote effective enantiodiscrimination (Scheme 2b).

Table 6. Scope: Unsymmetrically-substituted BINOL derivatives.

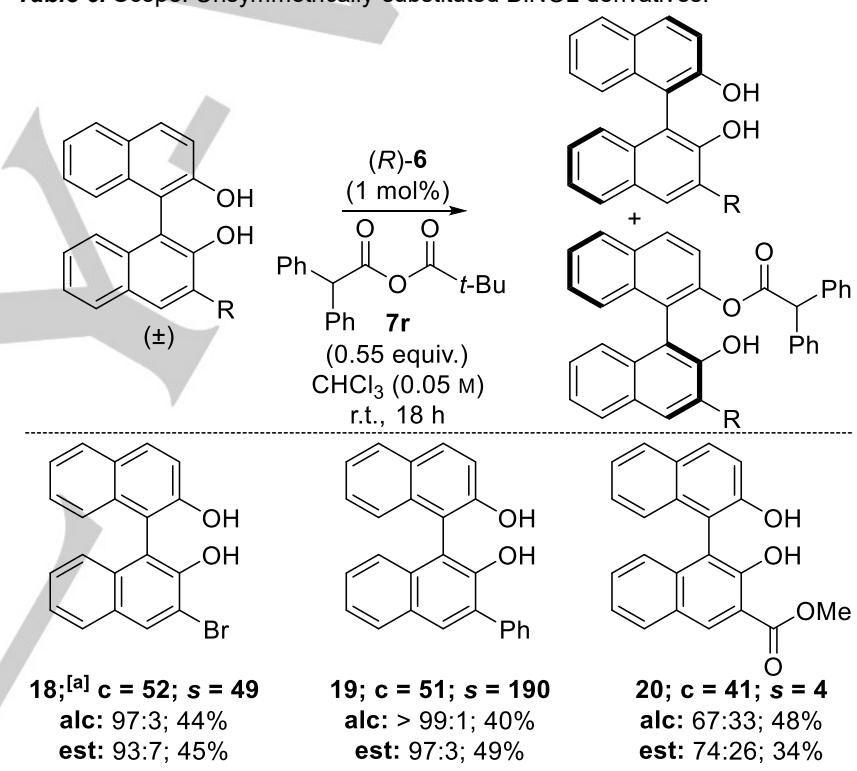

Conversion (c) and er determined by chiral HPLC analysis. $s$ calculated using equations given in ref. 6 . [a] PhMe used as solvent

Intrigued by the apparent differences in the regioselectivity of acylation of 3-bromo-substituted BINOL 18 using BTM 6, DMAP and an NHC catalyst, ${ }^{[14]}$ further control studies were performed (Scheme 4). Treatment of an enantioenriched sample of monoester constitutional isomer (S)-21 (93:7 er) with $i$ - $\mathrm{Pr}_{2} \mathrm{NEt}$ (10 $\mathrm{mol} \%$ ) resulted in equilibration to give a mixture of constitutional isomers 21 and 22 in a 77:23 ratio (Scheme 4a). HPLC analysis using a chiral support revealed both constitutional isomers were obtained with the same enantiomeric enrichment (93:7 er), indicating no racemization takes place during this acyl transfer process. To provide further insight, 21 was treated under various conditions, with the time taken to reach equilibrium assessed by ${ }^{1} \mathrm{H}$ NMR spectroscopy (Scheme $4 \mathrm{~b})$. Equilibration in the presence of $i$ - $\mathrm{Pr}_{2} \mathrm{NEt}(10 \mathrm{~mol} \%)$ was achieved after 15 minutes, whilst the use of DMAP (10 mol\%) required an extended reaction time of 1 hour to reach equilibrium. This difference in rate suggests equilibration most likely takes place through a Brønsted base-catalyzed process. ${ }^{[30]}$ 
Considering an equivalent of $i-\mathrm{Pr}_{2} \mathrm{NEt}$ was used in the NHCcatalyzed KR of biaryl diols (Scheme $1 \mathrm{~b}$ ), ${ }^{[14]}$ the mixture of constitutional isomers reported for the KR of $\mathbf{1 8}$ may not be representative of the regioselectivity of acylation using the $\mathrm{NHC}$ catalyst, but rather the position of equilibrium between the constitutional isomers. Finally, when monoester $\mathbf{2 1}$ was treated with rac-BTM 6 (10 mol\%) significantly slower equilibration was observed, with one week required to reach a 78:22 ratio of 21:22 The fact that constitutional isomer $\mathbf{2 2}$ was not observed under $\mathrm{KR}$ conditions may therefore be rationalized by the lower loading of BTM 6 used (1 mol\%), in addition to the formation of pivalic acid over the reaction course, which presumably inhibits this Brønsted base-catalyzed process.<smiles>O=C(Oc1ccc2ccccc2c1-c1c(O)c(Br)cc2ccccc12)C(P)c1ccccc1</smiles>
(S)-21
93:7 er

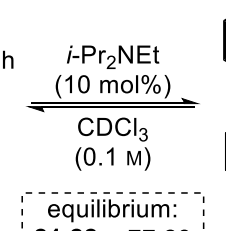

$21: 22=77: 23$

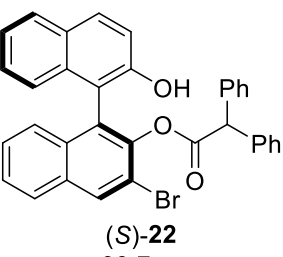

93:7 er

b)

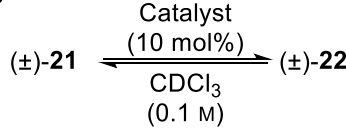

\begin{tabular}{cc} 
Catalyst & $\begin{array}{c}\text { Time to reach } \\
\text { equilibrium }\end{array}$ \\
\hline$i$ - $\mathrm{Pr}_{2} \mathrm{NEt}$ & $0.25 \mathrm{~h}$ \\
DMAP & $\begin{array}{c}1 \mathrm{~h} \\
\text { rac-BTM 6 }\end{array}$ \\
$168 \mathrm{~h}$
\end{tabular}

Scheme 4. Interconversion between constitutional isomeric esters $\mathbf{2 1}$ and $\mathbf{2 2 .}$

\section{Conclusions}

In summary, we have developed an operationally-simple method for the atropselective acylative KR of axially chiral biaryl diols using an isothiourea organocatalyst (generally $1 \mathrm{~mol} \%$ ) and a bench-stable mixed anhydride (2,2-diphenylacetic pivalic anhydride). The KR of a range of binaphthyl and biphenyl diols, in addition to a NOBIN derivative, is reported ( $s$ up to 190). Significant to the success of this method is the presence of two hydrogen bond donors in the substrate, with low conversion and selectivity observed in the attempted resolution of monoprotected diols. In addition, the acylation of 3,3'-disubstituted BINOL derivatives proved challenging, leading to the development of the regioselective acylation of unsymmetricallysubstituted BINOL derivatives bearing only a single 3-substituent A transition state model for acylation has been proposed to help rationalize the observed reactivity and enantiodiscrimination. The insights obtained through this work provides great promise for the development of other atropselective processes using isothiourea catalysis, with some of these avenues of research currently being explored within our group. ${ }^{[31]}$

\section{Acknowledgements}

The research leading to these results has received funding from the ERC under the European Union's Seventh Framework Programme (FP7/2007-2013)/E.R.C. grant agreement $n^{\circ}$ 279850. The Chinese Scholarship Scheme and University of St Andrews are thanked for a CSC Scholarship (S.Q.). A.D.S. thanks the Royal Society for a Wolfson Research Merit Award. We thank the EPSRC UK National Mass Spectrometry Facility at Swansea University.
Keywords: biaryl $\bullet$ kinetic resolution $\cdot$ enantioselectivity • regioselectivity $\cdot$ axial chirality

[1] a) G. Bringmann, C. Günther, M. Ochse, O. Schupp, S. Tasler in Progress in the Chemistry of Organic Natural Products, Vol. 82 (Eds. W. Herz, H. Falk, G. W. Kirby, R. E. Moore), Springer, Berlin, 2001, pp. 1-129; b) G. Bringmann, T. Gulder, T. A. M. Gulder, M. Breuning Chem. Rev. 2011, 111, 563-639; c) M. H. McCormick, W. M. Stark, G. E. Pittenger, R. C. Pittenger, J. M. McGuire, Antibiot. Annu. 1955, 56, 606-611; d) B. K. Hubbard, C. T. Walsh, Angew. Chem. Int. Ed. 2003 42, 730-765; Angew. Chem. 2003, 115, 752-789; e) K. P. Manfredi, J. W. Blunt, J. H. Cardellina II, J. B. McMahon, L. L. Pannell, G. M. Cragg, M. R. Boyd, J. Med. Chem. 1991, 34, 3402-3405.

[2] a) J. M. Brunel, Chem. Rev. 2005, 105, 857-897; b) S. G. Telfer, R. Kuroda, Coord. Chem. Rev. 2003, 242, 33-46.

[3] a) Y. Chen, S. Yekta, A. K. Yudin, Chem. Rev. 2003, 103, 3155-3212; b) M. Shibasaki, S. Matsunaga in Privileged Chiral Ligands and Catalysts (Ed.: Q. L. Zhou), Wiley, Hoboken, 2011, 295-332; c) K. Ding, H. Guo, X. Li, Y. Yuan, Y. Wang, Top Catal. 2005, 35, 105-116; d) E. M. Carreira, R. A. Singer, W. Lee, J. Am. Chem. Soc. 1994, 116, 88378838; e) J. J. Van Veldhuizen, S. B. Garber, J. S. Kingsbury, A. H. Hoveyda, J. Am. Chem. Soc. 2002, 124, 4954-4955; f) T. Ohkuma, M. Kurono in Privileged Chiral Ligands and Catalysts (Ed.: Q. L. Zhou), Wiley, Hoboken, 2011, 1-53

[4] a) G. Bringmann, A. J. Price Mortimer, P. A. Keller, M. J. Gresser, J. Garner, M. Breuning, Angew. Chem. Int. Ed. 2005, 44, 5384-5427; Angew. Chem. 2005, 117, 5518-5563; b) J. Wencel-Delord, A. Panossian, F. R. Leroux, F. Colobert, Chem. Soc. Rev. 2015, 44, 3418-3430.

[5] For reviews, see: a) H. Wang, Chirality 2010, 22, 827-837; b) P. Loxq E. Manoury, R. Poli, E. Deydier, A. Labande, Coord. Chem. Rev. 2016 308, 131-190; For selected examples, see: c) Q. X. Guo, Z. J. Wu, Z. B Luo, Q. Z. Liu, J. L. Ye, S. W. Luo, L. F. Cun, L. Z. Gong, J. Am. Chem. Soc. 2007, 129, 13927-13938; d) J. B. Hewgley, S. S. Stahl, M. C. Kozlowski, J. Am. Chem. Soc. 2008, 130, 12232-12233; e) H. Egami, T. Katsuki, J. Am. Chem. Soc. 2009, 131, 6082-6083; f) H. Egami, K. Matsumoto, T. Oguma, T. Kunisu, T. Katsuki, J. Am. Chem. Soc. 2010, 132, 13633-13635; g) S. Takizawa, J. Kodera, Y. yoshida, M. Sako, S. Breukers, D. Enders, H. Sasai, Tetrahedron 2014, 70, 1786-1793; h) S. Narute, R. Parnes, F. D. Toste, D. Pappo, J. Am. Chem. Soc. 2016, 138, 16553-16560.

[6] a) H. B. Kagan, J. C. Fiaud in Topics in Stereochemistry, Vol. 18 (Eds E. L. Eliel, S. H. Wilen), Wiley, New York, 1988, pp. 249-330; b) M. D. Greenhalgh, J. E. Taylor, A. D. Smith, Tetrahedron 2018, 74, 55545560

[7] For a review of KR and Dynamic KR (DKR) of biaryl compounds see: $G$. Ma, M. P. Sibi, Chem. Eur. J. 2015, 21, 11644-11657;

[8] a) Y. Fujimoto, H. Iwadate, N. Ikekawa, J. Chem. Soc. Chem. Commun. 1985, 1333-1334; b) S. Miyano, K. Kawahara, Y. Inoue, H. Hashimoto Chem. Lett. 1987, 355-356; c) K. Kawahara. M. Matsumoto, S. Miyano Chem. Lett. 1988, 1163-1164; d) N. Aoyagi, T. Izumi, Tetrahedron Lett. 2002, 43, 5529-5531; e) N. Aoyagi, S. Kawauchi, T. Izumi, Tetrahedron Lett. 2003, 44, 5609-5612; f) N. Aoyagi, T. Ohawada, T. Izumi, Tetrahedron Lett. 2003, 44, 8269-8272; g) T. Furutani, M. Hatsuda, R. Imashiro, M. Seki, Tetrahedron: Asymmetry 1999, 10, 4763-4768; h) M. Seki, T. Furutani, M. Hatsuda, R. Imashiro, Tetrahedron Lett. 2000, 41, 2149-2152; For an example of DKR of BINOL derivatives using a combination of a Ru racemization catalyst and an enzyme, see: G. A. I. Moustafa, Y. Oki, S. Akai, Angew. Chem. Int. Ed. 2018, 57, 1027810282.

[9] a) H. Aiyama, M. Tokunaga, J. Kiyosu, T. Iwasawa, Y. Obora, Y. Tsuji, J. Am. Chem. Soc. 2005, 127, 10474-10475; b) M. Schlosser, F. Bailly, J. Am. Chem. Soc. 2006, 128, 16042-16043; c) V. Bhat, S. Wang, B. M. Stolz, S. C. Virgil, J. Am. Chem. Soc. 2013, 135, 16829-16832; d) D.W. Gao, Q. Gu, S.-L. You, ACS Catal. 2014, 4, 2741-2745.

[10] a) S. Arseniyadis, M. Mahesh, P. McDaid, T. Hampel, S. G. Davey, A. C. Spivey, Collect. Czech. Chem. Commun. 2011, 76, 1239-1253; b) S. 
Shirakawa, X. Wu, K. Mauroka, Angew. Chem. Int. Ed. 2013, 52, 14200-14203; Angew. Chem. 2013, 125, 14450-14453; c) D. J. Cheng, L. Yan, S. K. Tian, M. Y. Wu, L. X. Wang, Z. L. Fan, S. C. Zheng, X. Y. Liu, B. Tan, Angew. Chem. Int. Ed. 2014, 53, 3684-3687; Angew. Chem. 2014, 126, 3758-3761.

[11] For reviews on Lewis base-catalyzed acyl transfer see: a) C. E. Müller P. R. Schreiner, Angew. Chem. Int. Ed. 2011, 50, 6012-6042; Angew. Chem. 2011, 123, 6136-6167; b) J. I. Murray, Z. Heckenast, A. C. Spivey in Lewis Base Catalysis in Organic Synthesis, Vol. 2 (Eds.: E. Vedejs, S. E. Denmark), Wiley-VCH, Weinheim, 2016, pp. 459-526.

[12] Selectivity factor $(s)$ is the most commonly-used metric to report the efficiency of a KR, and is defined as the rate constant for the fast reacting enantiomer divided by the rate constant for the slow reacting enantiomer $\left(s=k_{\text {fast }} / k_{\text {slow }}\right)$. See references $6 \mathrm{a}$ and $6 \mathrm{~b}$ for more details.

[13] a) G. Ma, J. Deng, M. P. Sibi, Angew. Chem. Int. Ed. 2014, 53, 1181811821; Angew. Chem. 2014, 126, 12012-12015; For a related example of DKR, see: G. Ma, C. Deng, J. Deng, M. P. Sibi, Org. Biomol. Chem. 2018, 16, 3121-3126

[14] S. Lu, S. B. Poh, Y. Zhao, Angew. Chem. Int. Ed. 2014, 53, 1104111045; Angew. Chem. 2014, 126, 11221-11225

[15] For a review on isothiourea catalysis see: J. Merad, J.-M. Pons, O. Chuzel, C. Bressy, Eur. J. Org. Chem. 2016, 5589-5610.

[16] a) V. B. Birman, X. Li, Org. Lett. 2006, 8, 1351-1354; b) M. Kobayashi, S. Okamoto, Tetrahedron Lett. 2006, 47, 4347-4350.

[17] A. S. Burns, A. J. Wagner, J. L. Fulton, K. Young, A. Zakarin, S. D. Rychnovsky, Org. Lett. 2017, 19, 2953-2956.

[18] a) V. B. Birman, L .Guo, Org. Lett. 2006, 8, 4859-4861; b) I. Shiina, K. Nakata, Tetrahedron Lett. 2007, 48, 8314-8317; c) V. B. Birman, X. Li, Org. Lett. 2008, 10, 1115-1118; d) I. Shiina, K. Nakata, M. Sugimoto, Y. Onda, T. Ikzumi, K. Ono, Heterocycles 2009, 77, 801-810; e) Y Zhang, V B. Birman, Adv. Synth. Catal. 2009, 351, 2525-2529; f) Q. Hu H. Zhou, X. Geng, P. Chen, Tetrahedron 2009, 65, 2232-2238; g) H. Zhou, Q. Hu, P. Chen, Tetrahedron 2010, 66, 6494-6499; h) I. Shiina, K. Nakata, K. Ono, M. Sugimoto, A. Sekiguchi, Chem. Eur. J. 2010, 16 167-172; i) K. Nakata, A. Sekiguchi, I. Shiina, Tetrahedron: Asymmetry 2011, 22, 1610-1619; j) I. Shiina, K. Ono, K. Nakata, Chem. Lett. 2011 40, 147-149; k) D. Belmessieri, C. Joannesse, P. A. Woods, C. MacGregor, C. Jones, C. D. Campbell, C. P. Johnson, N. Duguet, C. Concellón, R. A. Bragg, A. D. Smith, Org. Biomol. Chem. 2011, 9, 559570 ; I) X. Li, H. Jiang, E. W. Uffman, L. Guo, Y. Zhang, X. Yang, V. B. Birman, J. Org. Chem. 2012, 77, 1722-1737; m) K. Nakata, K. Gotoh, K. Ono, K. Futami, I. Shiina, Org. Lett. 2013, 15, 1170-1173; n) I. Shiina, K. Ono, T. Nakahara, Chem. Commun. 2013, 49, 10700; o) S. F. Musolino, O. S. Ojo, N. J. Westwood, J. E. Taylor, A. D. Smith, Chem. Eur. J. 2016, 22, 18916-18922; p) K. Nakata, E. Tokumaru, T. Saitoh, T. Nakahara, K. Ono, T. Murata, I. Shina, Heterocycles 2017, 95, 277289; q) T. Murata, T. Kawanishi, A. Sekiguchi, R. Ishikawa, K. Ono, K. Nakata, I. Shina, Molecules 2018, 23, 2003; r) R. M. Neyyappadath, R. Chisholm, M. D. Greenhalgh, C. Rodríguez-Escrich, M. A. Pericàs, G. Hähner, A. D. Smith, ACS Catal. 2018, 8, 1067-1075.

[19] a) M. D. Greenhalgh, S. M. Smith, D. M. Walden, J. E. Taylor, Z. Brice, E. R. T. Robinson, C. Fallan, D. B. Cordes, A. M. Z. Slawin, H. C. Richardson, M. A. Grove, P. H.-Y. Cheong, A. D. Smith, Angew. Chem. Int. Ed. 2018, 57, 3200-3206; Angew. Chem. 2018, 130, 3254-3260; b) N. R. Guha, R. M. Neyyappadath, M. D. Greenhalgh, R. Chisholm, S. M. Smith, M. L. McEvoy, C. M. Young, C. Rodríguez-Escrich, M. A. Pericàs, G. Hähner, A. D. Smith, Green Chem. 2018, 20, 4537-4546.

[20] For related computational studies see: a) X. Li, P. Liu, K. N. Houk, J. Am. Chem. Soc. 2008, 130, 13836-13837; b) I. Shiina, K. Nakata, K Ono, Y. Onda, M. Itagaki, J. Am. Chem. Soc. 2010, 132, 11629-11641; c) P. Liu, X. Yang, V. B. Birman, K. N. Houk, Org. Lett. 2012, 14, 32883291; d) X. Yang, P. Liu, K. N. Houk, V. B. Birman, Angew. Chem. Int. Ed. 2012, 51, 9638; Angew. Chem. 2012, 124, 9776-9642.

[21] a) B. R. Beno, K.-S. Yeung, M. D. Bartberger, L. D. Pennington, N. A. Meanwell, J. Med. Chem. 2015, 58, 4383-4438; b) V. B. Birman, X. Li, Z. Han, Org. Lett. 2007, 9, 37-40; c) M. E. Abbasov, B. M. Hudson, D. J. Tantillo, D. Romo, J. Am. Chem. Soc. 2014, 136, 4492-4495; d) E. R. T. Robinson, D. M. Walden, C. Fallan, M. D. Greenhalgh, P. H.-Y.
Cheong, A. D. Smith, Chem. Sci. 2016, 7, 6919-6927; e) T. H. West, D. M. Walden, J. E. Taylor, A. C. Brueckner, R. C. Johnson, P. H.-Y. Cheong, G. C. Lloyd-Jones, A. D. Smith, J. Am. Chem. Soc. 2017, 139 4366-4375; f) D. J. Pascoe, K. B. Ling, S. L. Cockroft, J. Am. Chem. Soc. 2017, 139, 15160-15167.

[22] a) S. Xu, I. Held, B. Kempf, H. Mayr, W. Steglich, H. Zipse, Chem. Eur. J. 2005, 11, 4751-4757; b) V. Lutz, J. Glatthaar, C. Würtele, M. Serafin H. Hausmann, P. R. Schreiner, Chem. Eur. J. 2009, 15, 8548-8557; c) E. Larionov, M. Mahesh, A. C. Spivey, Y. Wei, H. Zipse, J. Am. Chem. Soc. 2012, 134, 9390-9399; d) C. E. Cannizzaro, K. N. Houk, J. Am. Chem. Soc. 2002, 124, 7163-7169; e) R. C. Johnston, P. H.-Y. Cheong, Org. Biomol. Chem. 2013, 11, 5057-5064.

[23] C. Joannesse, C. P. Johnston, C. Concellón, C. Simal, D. Philp, A. D. Smith, Angew. Chem. Int. Ed. 2009, 48, 8914-8918; Angew. Chem. 2009, 121, 9076-9080.

[24] See the Supporting Information for details

[25] a) H. E. Eastman, C. Jamieson, A. J. B. Watson, Aldrichimica Acta 2015, 48, 51-55; b) D. Prat, A. Wells, J. Hayler, H. Sneddon, C. R. McElroy, S. Abou-Shehada, P. J. Dunn, Green Chem. 2016, 18, 288296.

[26] C. A. Hunter, Angew. Chem. Int. Ed. 2004, 43, 5310-5324; Angew. Chem. 2004, 116, 5424-5439.

[27] I. Shinna, R. Ibuka, M. Kubota, Chem. Lett. 2002, 31, 286-287.

[28] The origins behind how a mixed anhydride improves the selectivity of the KR are currently unknown. Possible explanations could include changes in the rate of alternative, less selective reaction pathways with each anhydride; or could originate from the nature of the counterion in the diastereomeric acylation TSs (see Scheme 2). The carboxylate counterion is known to play a significant role in stabilising the acylation TSs (see references 19a, 20,22), and thus different carboxylate counterions could in principle stabilise each diastereomeric TS to different extents, leading to a change in the magnitude of KR selectivity. To the best of our knowledge however there are currently no systematic studies into the magnitude or origin of this effect.

[29] The KR of a 3,3'-dibrominated $\mathrm{H}_{8}$-BINOL derivative was also attempted, however no conversion was obtained, consistent with the previous observation that substituents in the $3,3^{\prime}$ positions inhibit effective acylation.

[29] a) T. Rodima, I. Kaljurand, A. Pihl, V. Mäemets, I. Leito, I. A. Koppel, J. Org. Chem. 2002, 67, 1873-1881; b) I. Kaljurand, A. Kütt, L. Sooväli, T. Rodima, V. Mäemets, I. Leito, I. A. Koppel, J. Org. Chem. 2005, 70, 1019-1028.

[30] The research data underpinning this publication can be found at DOI https://doi.org/10.17630/e3c404a2-7482-4ebe-a2e2-f320e55781a2. 
Entry for the Table of Contents (Please choose one layout)

Layout 1:

\section{FULL PAPER}

Text for Table of Contents

Layout 2:

\section{FULL PAPER}

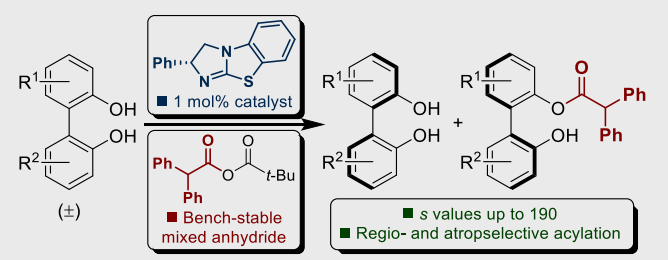

The kinetic resolution of unprotected 1,1'-biaryl-2,2'-diol derivatives is reported, in which a combination of a bench-stable mixed anhydride and $1 \mathrm{~mol} \%$ of a commercially-available isothiourea catalyst is required. This operationally simple process provides access to axially-chiral diols in highly enantioenriched form ( $s$ values up to 190).
Author(s), Corresponding Author(s)*

\section{Page No. - Page No.}

Title

((Insert TOC Graphic here: max. width: $5.5 \mathrm{~cm}$; max. height: $5.0 \mathrm{~cm}$ ))

Shen Qu, Mark. D. Greenhalgh and Andrew. D. Smith*

Page No. - Page No.

Isothiourea-Catalyzed Regioselective Acylative Kinetic Resolution of Axially Chiral Biaryl Diols 